\title{
Social Worker Roles with Refugees
}

Khalil Abdel Maksoud Abdel Hamid Ibrahim (PhD)

Social work department- Social Sciences College

Umm Alqura university- Saudi Arabia 


\section{Abstract}

Social Work profession has been committed to the defense and promotion of Human Rights. Social workers focus on working with the most vulnerable populations across the world regardless of ethnicity, language, gender, ideology, age, physical ability, status or any other condition liable to lead to discrimination. Social work pioneers such as Jane Addams, Grace and Edith Abbott, have left a legacy of dedicated and committed work with new immigrants. Settlement houses, neighborhood centers. In recent years social work face a challenge how to continue in its role with refugees and asylum seekers. This paper discuss who refugee, what international organizations support and work with them, social work role with refugees, and challenges for Social Work Practice with them.

Keywords: Refugees- Social Worker Roles- international social work INTRODUCTION

Growing refugee numbers considering worldwide social crisis which effects all communities, all age group there are 42,5million people were forced to leave their homes every day because of conflict or persecution (UNHCR, 2016, p. 1)

Worldwide there were $86 \%$ of the world's refugees are hosted by developing countries and more than half of the world's refugees are children (51\%): the highest figure in over a decade refugee. (Refugee Council ,2016,p.3)

In 2014, global displacement reached historic levels: 59.5 million people were forced to flee their homes; 8.3 million people were forced to flee: the highest annual increase and more than half (53\%) of the world's refugees are from just three countries: Syria, Afghanistan and Somalia and around 80,000 refugees arrive in Europe in first six weeks of 2016 (UNHCR, 2016, p.5)

Since the beginning of the Syrian conflict in 2011, more than 2 million refugees have been displaced from their homes. According to the United Nations High Commissioner for Refugees (UNHCR), as a result of the conflict more than 6.5 million people within Syria require immediate humanitarian assistance, and an estimated 9.3 million are in need of aid. The sheer scope of this complex situation makes it among the largest humanitarian crises in recent history (UNHCR, 2016, p. 5). 
Migration is a global issue that affects us all -whether as an emigratory or immigratory country. For social work, migration raises many issues from the practical - how to work with individuals, families, groups and different cultures often displaced in traumatic circumstances - to the philosophical and axiological. Values are challenged as states struggle to adjust to changing migratory patterns; discrimination and oppression may be embedded in structural practices and within the structures that deploy (and employ) social workers.(Valtonen,2008,p.8) So we need to understanding of immigration as a complex phenomenon is essential if social workers are to offer appropriate supports. (Drachman\& Paulino, 2004, 4).

From its beginning, the Social Work profession has been committed to the defense and promotion of Human Rights. Social workers focus on working with the most vulnerable populations across the world regardless of ethnicity, language, gender, sexual preference, religion or belief, ideology, age, physical ability, status or any other condition liable to lead to discrimination. (http://ifsw.org/policies)

Social work pioneers such as Jane Addams, Grace and Edith Abbott, and Sophie Breckinridge have left a legacy of dedicated and committed work with new immigrants. Settlement houses, neighborhood centers, and sectarian and other voluntary agencies have provided needed services to immigrant groups struggling to adapt to their new homeland, for example, the "citizenship classes" conducted in settlement houses aimed at enabling immigrants to become "good" citizens. The profession's efforts thus complemented the muchcherished ideal of the American past, which was the ideal of the melting pot. Pioneers in social work assumed the roles of mediators and advocates on behalf of the immigrants in their adaptation to their new environment. (Pallassana R. Balgopal, 2000, p.15)

Immigration has always been and continues to be central to social work services because immigrants are vulnerable to all types of substandard living conditions and abuses, including child-labor, prostitution and human trafficking. Furthermore, 'social workers are in a good position to foster deliberation by presenting more positive points of view on the immigration phenomenon', particularly in the area of immigration policy. Issues of authority and power often 
preclude the full utilization of formal social work services by immigrants. In spite of this, in the direct practice arena, social workers could play a more central role in serving immigrants and in incorporating anti-oppressive practices in an area often fraught by a law enforcement mentality. (Brawle\& Zorita, 2011, pp. 17-28)

The values of social work, acknowledging principles of both social justice and the dignity and worth of each individual person, likewise enable social work to focus on the importance of ensuring that responses to refugees are well considered and appropriate.

Social workers are trained and skilled in helping people through dramatic change in their lives and on healing and building communities that are under pressure or suffer from racial tension. From their worldwide on the ground experience, social workers have witnessed which polices enable refugees to positively integrate into a new environment, and which policies undermine their aspirations and the wellbeing of the communities that they join. Social workers encountering refugees during resettlement or in the years following the official resettlement period will need to assist them in coping with these multiple cultural and emotional challenges, as well as their needs for help with housing, job searching, and other basics (Healey, 2008 , p.9). The social worker play vital role in order to meet physical needs of refugees, for food, clothing, health care and shelter, have to be met, However, policies also need to focus on the psychosocial needs and related social functioning of refugees, as those aspects of human well-being are the central concerns of the social profession. (International Federation of Social Workers, 2016)

\section{A refugee:}

A refugee is a person who flees their home country due to a "wellfounded fear of being persecuted for reasons of race, religion, nationality, membership of a particular social group or political opinion According to (The United Nations High Commissioner on refugee, 2016, 2)

According to the Geneva Convention on Refugees is a person who is outside their country of citizenship because they have wellfounded grounds for fear of persecution because of their race, religion, nationality, membership of a particular social group or political opinion, and is unable to obtain sanctuary from their home country or, owing to such fear, is unwilling to avail themselves of the protection 
of that country (Geneva Convention on Refugees,2014). By definition, refugees are individuals who are escaping danger or persecution in their home countries due to racial, religious, and political reasons, and look for shelter and safety in a new land. Most refugees experience traumatizing events such as witnessing killing, wars, rape, imprisonments, separation from family members, etc. (Eltaiba, 2014,p.398)

\section{Root Causes of Refugee and Immigration Movements:}

An estimated 13.9 million people were newly displaced due to conflict or persecution, including 2.9 million new refugees, (UNHCR 2014, 4).The decision of immigrations is usually caused by internal conditions that make life unbearable in the home country, However, where these conditions exist, external conditions may also contribute to the decision to leave such as rumors about the availability of a better life elsewhere. Among the most common causes of refugee and immigration movements are: war, poverty, human rights violations, and mistreatment of minorities, these causes are most often found in combination with each other, ethnic cleansing leads to war; human rights violations lead to poverty, (Refugees and Immigration Ministers, 2016,p.10)

\section{Global Refugees Needs}

Refugees have multiple needs, with many escaping severe persecution, and/or torture and enduring considerable hardship both in reaching the refuges countries and once they have arrived (Perry, 2005; Patel and Mahatanti, 2007), with many communities facing high levels of deprivation and exclusion (Palmer et al, 2008,p.55).

The Institute of Community Cohesion (ICOCO, 2008) has identified the key issues for public services for migrants in general, which are relevant to provision for refugees as:

Child protection: the complexities of ensuring effective safeguarding of children in transient families, which are exacerbated by language and cross-cultural issues.

- Language barriers: meeting the basic information needs, translation and interpretation, supporting complex advice needs and communicating in emergencies.

- Housing: poor-quality accommodation with people living in overcrowded or unsuitable properties in a poor state of repair, sometimes with a high fire risk or other health and safety problems. 
- Community cohesion: tensions and conflicts between migrants, including forced migrants and the host communities.

- Community safety: migrants are more likely to be victims of crime than Perpetrators.

- Health: the impact is felt on Accident \& Emergency (A\&E), maternity services, and mental health services, particularly for asylum seekers and refugees who have experienced trauma.

\section{Some Possible Consequences of Refugee Experience:}

1.Psychological trauma due to persecution, war or civil conflict, and the circumstances leading to and surrounding it.

2.Social dislocation.

3.Loss, including separation from family and friends.

4.Insecurity, including real actual or threatened physical violence and rape.

5.Overcrowding, poor hygiene and under-nutrition, particularly for those who have been imprisoned or in camps.

6.Poor medical care, due to destruction of infrastructure and disruption to health services by fighting in the country of origin, and through limited access to health care whilst fleeing and whilst seeking asylum.

7.Disrupted education of children.

8.Lost or interrupted careers for adults.

\section{Global Population Figure by Region}

By the end of 2014, 59.5 million people were forcibly displaced, compared to 51.2 million a year earlier. Turkey has now become the world's largest refugee-hosting nation with 1.59 million, due to the conflict in neighboring Syria. However, when it comes to refugees per capita, Lebanon is in first place by a considerable distance. There are an estimated 1.15 million refugees in Lebanon altogether, equating to 232 per 1,000 inhabitants, (UNHCR, 2014) The Countries with the Most Refuges Per Capita: 


\section{The Countries With The Most Refugees Per Capita}

Number of refugees per 1,000 inhabitants in 2014

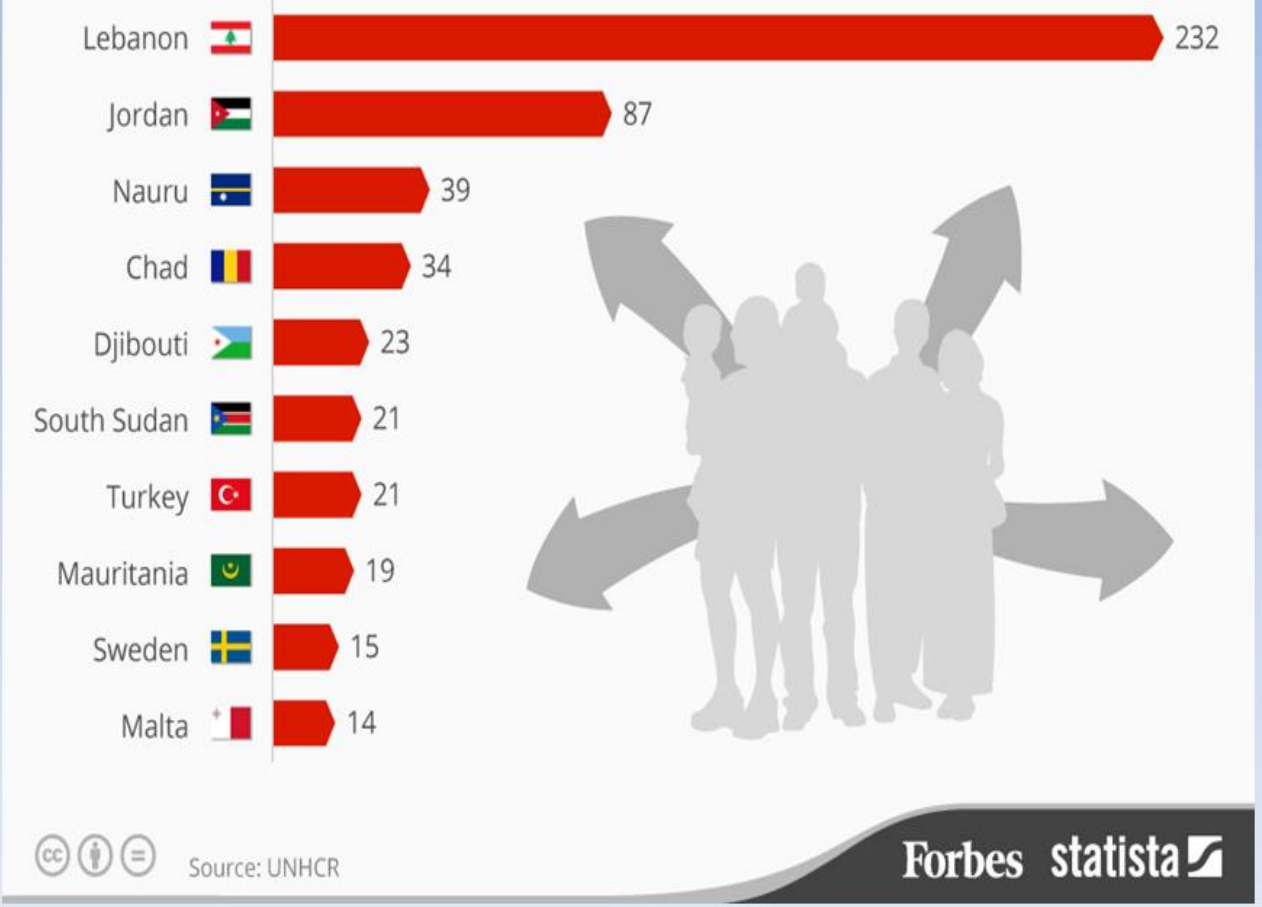

United Nations High Commissioner for Refugees: (2014): The Countries with the Most Refuges Per Capita.

\section{Refugee Population by Country or Territory of Asylum}

Refugees are people who are recognized as refugees under the 1951 Convention Relating to the Status of Refugees or its 1967 Protocol, the 1969 Organization of African Unity Convention Governing the Specific Aspects of Refugee Problems in Africa, people recognized as refugees in accordance with the UNHCR statute, people granted refugee-like humanitarian status, and people provided temporary protection. (UNHCR, 2016)

Asylum seekers--people who have applied for asylum or refugee status and who have not yet received a decision or who are registered as asylum seekers--are excluded. Palestinian refugees are people (and their descendants) whose residence was Palestine between June 1946 and May 1948 and who lost their homes and means of livelihood as a result of the 1948 Arab-Israeli conflict, country of 
asylum is the country where an asylum claim was filed and granted, (World Bank Group, 2016).

\section{Social Worker Activities with Refugee Worldwide:}

The social work profession grew enormously in response to the refugee crisis following the Second World War and since that time social workers have been supporting refugees and migrants in their journeys and transitions to new communities and societies. The current crisis is no exception with social workers in all the affected countries applying their knowledge and skills at all points of the refugees transition and with the communities where they seek asylum.

Social work as a profession clearly has much to offer in services for refugees from a skill base that integrates intra-personal and inter-personal helping with the practicalities of assisting people to negotiate their way around the social Welfare system, social workers can respond to the complex needs of refugees within an understanding of the wider context of family relationships and social institution (WHO, 2004)

Social care is defined by the Social Care Institute for excellence (SCIE) as 'the provision of social work, personal care (but not nursing or medical care), protection or social support services to children in need or at risk and their families and careers, or adults at risk or with needs arising from illness, disability, old age or poverty and their families or other careers, That provision may have one or more of the following aims: to protect service users, to preserve or advance physical or mental health, to promote independence and social inclusion, to improve opportunities and life chances, to strengthen families and protect human rights in relation to people's social needs. (Social Care Institute, 2010) Government policy and public attitudes, plus the psychological consequences of the pre-flight experience and subsequent experience of living in exile, have thus been linked to the need for social care in relation to mental health problems (Watters and Ingleby,2004)

\section{Refugee Resettlement and Social Worker Activities:}

Working toward fair and just immigration and refugee policies is important to the profession of social work and essential to the realization of human rights, social workers recognize migration as a complex social, cultural, and political process, In the many roles played by social workers, as both policy advocates and direct service providers, we impact immigrant and refugee populations and policy, 
social workers may design and coordinate community support programs for refugee families both in the U.S. and in other countries, advocate for stronger refugee resettlement services or carry out research.

Social workers assist newly arrived refugees in roles such as resettlement caseworkers or job developers, internationally, social workers may work with a humanitarian aid organization and coordinate psychosocial programs for children in refugee camps or work for an organization such as UNICEF or the UN High Commissioner for Refugees (UNHCR) to affect policy and design programs. The provision of safe, age-appropriate accommodation under section 20 of the 1989 Children Act, access to age-appropriate training and education and leisure activities, and assessment and access to appropriate services for children and young people who have been trafficked are the main role on social workers (Scie, S.,2010, Social care for refugees and asylum seekers,p.8)

Interventions should recognize and build on the strengths of refugees, community and refugee organizations often facilitate peer support networks and provide English language classes and other education and support that can help promote social inclusion and wellbeing (Social Care Institute, 2010,p.41)

\section{Global Social Worker Organizations Role with Refugees:}

The International Federation of Social Workers (IFSW) is a global organization striving for social justice, human rights and social development through the promotion of social work, best practice models and the facilitation of international cooperation.

(IFSW) supports its 116 country members by providing a global voice for the profession, IFSW has been granted Special Consultative Status by the Economic and Social Council (ECOSOC) of the United Nations and the United Nations Children's Fund (UNICEF). In addition, IFSW is working with the World Health Organization (WHO), the Office of the United Nations High Commissioner for Refugees (UNHCR), the Office of the United Nations High Commissioner for Human Rights (OHCHR). (International Federation of Social Worker, 2016)

\section{United Nations High Commissioner for Refugees:}

Protect refugees and resolve refugee problems worldwide. Its primary purpose is to safeguard the rights and well-being of refugees. It strives to ensure that everyone can exercise the right to seek asylum 
and find safe refuge in another State, with the option to return home voluntarily, integrate locally or to resettle in a third country it also has a mandate to help stateless people. Since 1950, the agency has helped tens of millions of people restart their lives. Today, a staff of more than 9,300 people in 123 countries continues to help and protect millions of refugees, returnees, internally displaced and stateless people.

\section{The Impact of Refugee Experience}

Refugees have suffered many hardships and or deals, in their home country they often lived under life-threatening circumstances such as poverty and lack of medical care, in times of conflict they have been exposed to, for example, serious injury, combat situations, rape, imprisonment, torture, separation and even the murder of close relatives.

Posttraumatic Stress Disorder (PTSD), which was previously defined as the consequence of a traumatic event or series of these events characterized by intrusive memories of the trauma and symptoms of avoidance and numbing, and hyper-arousal (American Psychiatric Association, 2000).

Even though refugees resettled in western countries are ten times more likely to have PTSD than age-matched general populations Complex PTSD may be the result of exposure to repeated or prolonged experiences or multiple forms of interpersonal trauma. Complex PTSD is characterized by the core symptoms of PTSD in conjunction with five domains of disturbances in self-regulatory capacities (emotion regulation difficulties, disturbances in relational capacities, alterations in attention and consciousness.

\section{Social work with immigrants' definition}

Social work with immigrants defines as "a relatively broad Complex of targeted activities that are aimed at finding a lasting solution to the situation of individuals, families and an immigrant community as a whole, that is, in particular, their adaptation and optionally inclusion into a new society. In addition, social work also includes help, support and finding solutions to immigrants with international protection procedure. (Zakov, Levicka, Legersky, 2015,p.8)

\section{What Types of clients in this field?}

By definition, refugees are individuals who are escaping danger or persecution in their home countries due to racial, religious, 
and political reasons, and look for shelter and safety in a new land. Most refugees experience traumatizing events such as witnessing killing, wars, rape, imprisonments, separation from family members, etc.

They are faced with considerable challenges in settling into new countries and many express feelings of anger, sadness, anxiety, vulnerability, and difficulty in interpersonal relationships Clinical research showed high incidence of post-traumatic experiences among refugees (Tseng 2003; Kinzie 2009). All this necessitates that the practitioner pays attention to the earlier stages of the professional relationship prior to identifying the problems and formulating strategies in the context. (Eltaiba, 2014, 400)

\section{Trauma:}

Psychological consequences of the refugee experience: ( NSW Refugee Health Service, 2004,p.14)

Refugees react and cope with trauma differently. Not all develop post-trauma symptoms. Some may only experience the impact of trauma at a later time, as a result of additional stresses.

Common reactions after traumatic life events include: - anxiety - panic attacks; startle responses. - Flashbacks. - Depression. - Grief reactions. - Dissociation or numbing. - sleeping problems irritability, or aggressiveness. - Emotional stress. - Eating disorders. - Psychosexual problems. - Inability to plan for the future; Pre-occupation with the past.

Some people may also have symptoms of post-traumatic stress disorder (PTSD), including:

Intrusive thoughts, memories, flashbacks and nightmares of traumatic/persecutory content

- Numbing and blocking responses such as avoiding thoughts, memories, people and situations that trigger traumatic memories.

- hyper-arousal symptoms such as sleeping, memory and concentration problems, startle responses, and irritability.

All refugees had suffered extremes of loss; loss of country, culture, language, Home, intimate relationships, possessions, status and role. (Clark, 2006, p. 379).

The refugee trauma divided into at least four phases which have been identified as (Papadopoulos, 2003, p. 45)

- Anticipation: when people sense the impeding danger and try to decide how best to avoid it. 
- Devastating Events: this is the phase of actual violence, when the enemy attacks and destroys, and the refugees flee.

- Survival : when refugees are safe from danger but live in temporary accommodation and uncertainty, and

- Adjustment: when refugees try to adjust to a new life in the receiving country.

Because of the difficulties associated with the refugee experience, researchers have linked the amount of trauma refugees experience with poor emotional outcomes. It is not surprising, therefore, that research indicates "higher rates of symptoms and mental disorders in refugees, compared with the general population" (Williams \&Berry, 2004, p.85)

\section{Social Work Role toward Traumatic Refugees:}

Social work as a profession clearly has much to offer in services for refugees. From a skill base that integrates intra-personal and inter-personal helping with the practicalities of assisting people to negotiate their way around the social welfare system, social workers can respond to the complex needs of refugees within an understanding of the wider context of family relationships and social institutions.

Social workers are ideally placed to structure services which respond to the special needs of refugee families, family support services, play groups, support groups, recreational activities such as choirs, and traditional practices, such as massage and acupuncture, all contribute to the healing process, Safe places, such as the school, are seen as an ideal forum in which early interventions can be coordinated (Centre for Population Mental Health Research2003).

As one of the most important task of social work with immigrants was described social assistance and social counseling. Accompanying the client to doctors, police station, offices, helping him or her to arrange living is seen as essential. (Zakova, M., Levicka, K., Legersky, D 2015, p.86)

\section{Challenges for Social Work Practice:}

Further barriers exist to accessing culturally relevant and appropriate mental health support and there is a call for identifying and sharing good practice (Social Perspectives Network and London Development Centre, 2006, p.12). Although there is comparatively little research on refugees with disabilities, that which exists reports that they face multiple disadvantage and a lack of basic social care provision can also contribute to the experience of hardship and 
poverty (Roberts and Harris, 2002; Harris, 2003, p.62). Social workers are often stopped from effectively assisting clients due to punitive laws and policies denying access to needed resources, social workers should become familiar with the dynamics of migration as well as the implications of immigration policy on individuals and families in order to effectively support immigrants and refugees in the U.S. and internationally, The lack of appropriate resources, such as materials and workers trained to respond to the needs refugee families, children and young people, either services do not exist, or are stretched to breaking point. The challenges posed to social work practice by refugee families is great, but the social work profession is ideally placed to provide the comprehensive range of well co-coordinated services which this group need, social workers are trained to respond to emotional needs and not to psycho-pathologies behaviors.

\section{REFERENCES}

International Federation of Social Workers (2016)World Social Work Day, NY.

Beth Humphries, reviewer, Diane Drachman and Ana Paulino (Eds) Immigrants and Social Work: Thinking beyond the Borders of the United States (2004) New York: Hawarth Press.

Centre for Population Mental Health Research at the University of New South Wales.

Emilia E. Martinez-Brawley \& Paz M.-B. Zorita (2011) Immigration and Social Work: Contrasting Practice and Education, Social Work Education Vol. 30, No. 1, February.

Healy, L. (2008). International social work: Professional action in an interdependent world. New York: Oxford University Press

Hugman, R, (2004) A guide for Social Workers Working with Refugees, New South Wales.

Institute of Community Cohesion (2008) Estimating the scale and impacts of migration at a local level, London: Local Government Association.

Jonathan Parker reviewer, Kathleen Valtonen (2008) Social Work and Migration: Immigrant and Refugee Settlement. Aldershot: Ashgate, Media Release(2004): 'Temporary protection visas compromise refugees' health: new research', 
http://www.unsw.edu.au/news/pad/articles/2004/jan/TPV_Health.h tml,

http://www.refugeecouncil.org.uk/latest/news/4350 top10 global facts a bout refugees refugees

Eltaiba, Nada (2014): Counseling with Muslim Refugees: Building Rapport, Journal of Social Work Practice, 2014 Vol. 28, No. 4, 397403, http://dx.doi.org/10.1080/02650533.2013.875523.

NSW Refugee Health Service and NSW Service for the Treatment and Rehabilitation of Torture and Trauma Survivors (2004): Working with Refugees" A guide for Social Workers" Sydney Australia September. Office of the United Nations High Commissioner for Refugees (UNHCR), (2016) Communications and Public Information Service.

Pallassana R. Balgopal (2000) Social Work Practice with immigrants and Refugees, Columbia University press New York.

Refugees and Immigration Ministers, (2016): Root Causes of Refugee and Immigration Movements Christian Church, Disciples of Christ www.unhcr.org/statistics/populationdatabase.

René D. Drumm PhD , Sharon W. Pittman \& Shelly Perry (2004) Social Work Interventions in Refugee Camps, Journal of Social Service Research, 30:2, 67-92, DOI: 10.1300/J079v30n02_05

Renos K. Papadopoulos (2003): refugees, home and trauma -inPapadopoulos, Renos, ed. Therapeutic Care for Refugees: No Place Like Home. London, GBR: Karnac Books.

The Social Care Institute(2010): Excellence presents best practice in working with refugees and asylum seekers with a human rights-based approach

United Nations High Commissioner for Refugees (UNHCR), Statistical Yearbook and data files, complemented by statistics on Palestinian refugees under the mandate of the UNRWA as published on its website. Data from UNHCR are available online at: www.unhcr.org/statistics/populationdatabase.

Val Clark(2006): Group Work Practice with Australia's Asylum Seekers, Australian Social Work, Vol. 59, No. 4, December. 
Zakova, M., Levicka, K., Legersky, D. (2015). Identity of Social Workers Working with Immigrants with an International Protection in Slovakia. Revista Romaneasca pentru Educatie Multidimensionala, 7(1).http://ifsw.org/policies. 